Japanese Experience with Gamma Knife Radiosurgery 


\section{Progress in Neurological Surgery}

Vol. 22

Series Editor

L. Dade Lunsford Pittsburgh, Pa. 


\section{Japanese Experience with Gamma Knife Radiosurgery}

Volume Editor

Masaaki Yamamoto Hitachi-naka

With a Foreword by

Kintomo Takakura Tokyo

109 figures, 16 in color, and 53 tables, 2009

KARGER

Basel · Freiburg · Paris · London · New York · Bangalore .

Bangkok · Shanghai · Singapore · Tokyo - Sydney 


\title{
Progress in Neurological Surgery
}

\author{
Masaaki Yamamoto, MD, PhD \\ Katsuta Hospital, Mito GammaHouse \\ Hitachi-naka, Ibaraki, Japan
}

\author{
Library of Congress Cataloging-in-Publication Data \\ Japanese experience with gamma knife radiosurgery / volume editor, Masaaki \\ Yamamoto, with a foreword by K. Takakura \\ p. ; cm. -- (Progress in neurological surgery; vol. 22) \\ Includes bibliographical references and index. \\ ISBN 978-3-8055-8604-7 (hard cover : alk. paper) \\ 1. Radiosurgery--Japan. I. Yamamoto, Masaaki. \\ [DNLM: 1. Radiosurgery--methods--Japan. WL 368 J35 2008 / W1 PR673 v. 22 \\ 2009] \\ RD594.15.J36 2009 \\ $617.4^{\prime} 810590952--d c 22$ \\ 2008018520
}

Bibliographic Indices. This publication is listed in bibliographic services, including Current Contents ${ }^{\circledast}$

Disclaimer. The statements, opinions and data contained in this publication are solely those of the individual authors and contributors and not of the publisher and the editor(s). The appearance of advertisements in the book is not a warranty, endorsement, or approval of the products or services advertised or of their effectiveness, quality or safety. The publisher and the editor(s) disclaim responsibility for any injury to persons or property resulting from any ideas, methods, instructions or products referred to in the content or advertisements.

Drug Dosage. The authors and the publisher have exerted every effort to ensure that drug selection and dosage set forth in this text are in accord with current recommendations and practice at the time of publication. However, in view of ongoing research, changes in government regulations, and the constant flow of information relating to drug therapy and drug reactions, the reader is urged to check the package insert for each drug for any change in indications and dosage and for added warnings and precautions. This is particularly important when the recommended agent is a new and/or infrequently employed drug.

All rights reserved. No part of this publication may be translated into other languages, reproduced or utilized in any form or by any means electronic or mechanical, including photocopying, recording, microcopying, or by any information storage and retrieval system, without permission in writing from the publisher.

(c) Copyright 2009 by S. Karger AG, P.O. Box, CH-4009 Basel (Switzerland)

www.karger.com

Printed in Switzerland on acid-free and non-aging paper (ISO 9706) by Reinhardt Druck, Basel

ISSN 0079-6492

ISBN 978-3-8055-8604-7

e-ISBN 978-3-8055-8605-4 


\section{Contents}

VII Acknowledgement

vIII Series Editor's Note

Lunsford, L.D. (Pittsburgh, Pa.)

IX Foreword

Takakura, K. (Tokyo)

xı Preface

Yamamoto, M. (Hitachi-naka)

1 History and Present Status of Gamma Knife Radiosurgery in Japan Otto, S. (Kobe)

11 Dose Selection for Optimal Treatment Results and Avoidance of Complications

Nagano, H. (Tokyo); Nakayama, S. (Odawara); Shuto, T.; Asada, H.; Inomori, S. (Yokohama)

20 Gamma Knife Radiosurgery for Arteriovenous Malformations: The Furukawa Experience

Jokura, H.; Kawagishi, J.; Sugai, K.; Akabane, A.; Boku, N.; Takahashi, K. (Osaki)

31 Radiosurgery for Cavernous Malformations in Basal Ganglia, Thalamus and Brainstem

Kida, Y. (Komaki)

38 Radiosurgery for Dural Arteriovenous Fistula Kida, Y. (Komaki)

45 Gamma Knife Radiosurgery for Vestibular Schwannomas

Fukuoka, S.; Takanashi, M.; Hojyo, A.; Konishi, M.; Tanaka, C.;

Nakamura, H. (Sapporo)

63 Long-Term Results of Gamma Knife Radiosurgery for 100 Consecutive Cases of Craniopharyngioma and a Treatment Strategy

Kobayashi, T. (Nagoya) 
77 Long-Term Results of Stereotactic Gamma Knife Radiosurgery for Pituitary Adenomas. Specific Strategies for Different Types of Adenoma Kobayashi, T. (Nagoya)

96 Gamma Knife Radiosurgery for Skull-Base Meningiomas

Takanashi, M.; Fukuoka, S.; Hojyo, A.; Sasaki, T.; Nakagawara, J.;

Nakamura, H. (Sapporo)

112 Other Skull-Base Tumors

Inoue, H.K. (Fujioka)

122 Radiosurgery for Intracranial Gliomas

Kida, Y.; Yoshimoto, M.; Hasegawa, T. (Komaki)

129 Gamma Knife Radiosurgery for Other Primary Intra-Axial Tumors Iwai, Y.; Yamanaka, K. (Osaka)

142 Metastatic Brain Tumors: Lung Cancer Serizawa, T. (Ichihara/Tokyo)

154 Gamma Knife Radiosurgery for Brain Metastases of Non-Lung Cancer Origin: Focusing on Multiple Brain Lesions

Yamamoto, M.; Barfod, B.E.; Urakawa, Y. (Hitachi-naka)

170 Treatment of Functional Disorders with Gamma Knife Thalamotomy Ohye, C.; Shibazaki, T. (Takasaki)

182 Trigeminal Neuralgia Hayashi, M. (Tokyo)

191 Author Index

193 Subject Index 


\section{Editor}

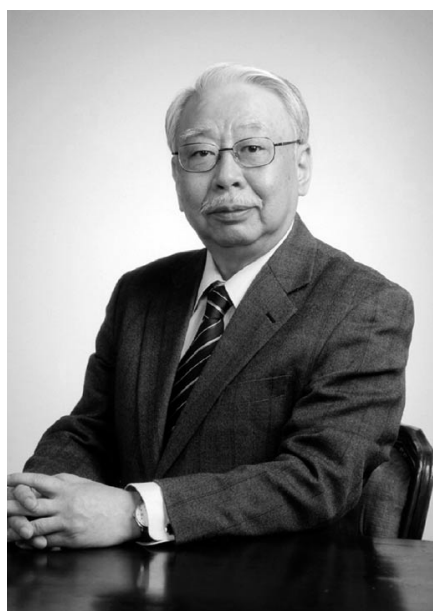

Masaaki Yamamoto
Honorary Editor

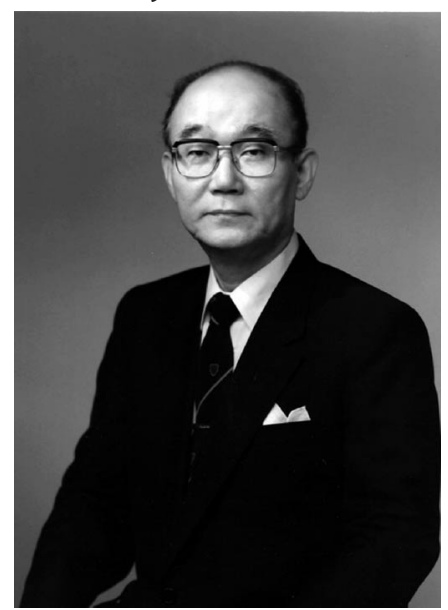

Kintomo Takakura

\section{Co-Editors}

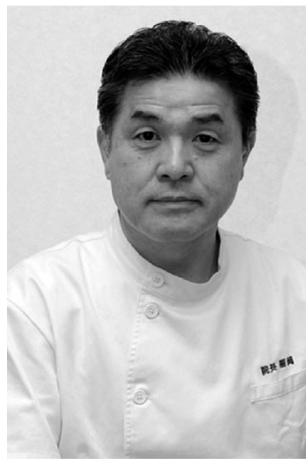

Seiji Fukuoka

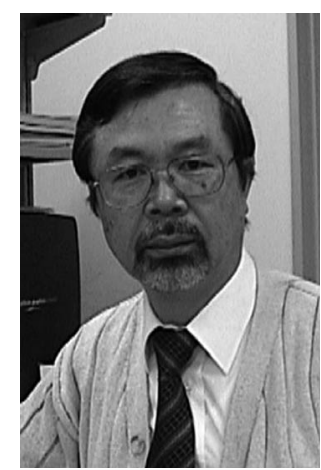

Hiroshi K. Inoue

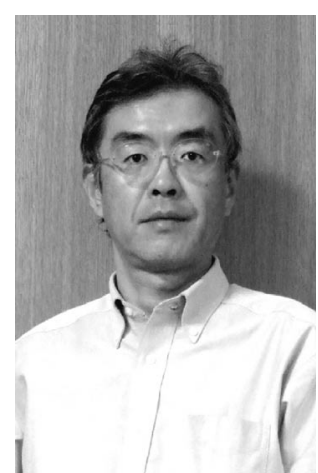

Hidefumi Jokura

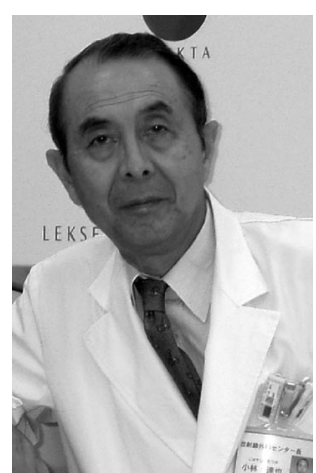

Tatsuya Kobayashi

\section{Acknowledgement}

The editor deeply appreciates the invaluable support of four co-editors, Drs. Seiji Fukuoka, Hiroshi K. Inoue, Hidefumi Jokura and Tatsuya Kobayashi, in the preparation of this publication. The editor is also extremely grateful to Honorary Editor Kintomo Takakura for his financial support through the Japan Brain Foundation. 


\section{Series Editor's Note}

Some years ago, Dr. Masaaki Yamamoto, working with many outstanding colleagues in Japan, became one of the early innovators in radiosurgery in his country. Along with Professor Takakura at the University of Tokyo, Professor Kobayashi at Nagoya, and a number of additional outstanding pioneers in radiosurgery, the field of radiosurgery was begun in Japan using the Leksell Gamma Knife in 1988 and 1989. Prior to this, many Japanese patients had been to Sweden to receive gamma knife brain surgery. The introduction of gamma knife radiosurgery in Japan required extensive efforts on the part of Professor Takakura, working with the appropriate government ministries to secure approval for installation, and many months later, reimbursement from the National Health Insurance Program. The authors of this volume have reported their experience with radiosurgery in Japan during the past 20 years. I knew that this book was in production only relatively recently, but believed that it sits well within the framework of the almost annual volumes of Progress in Neurological Surgery which are produced by Karger. As the Series Editor, I prevailed upon Dr. Yamamoto and his colleagues to place this summary of experience in Japan within the framework of the series of Progress in Neurological Surgery, volume 22. I hope that you will enjoy reading about these initial, and continuing pioneering efforts related to radiosurgery in Japan.

L. Dade Lunsford, MD

Pittsburgh, Pa., USA 


\section{Foreword}

In my career of five decades as a neurosurgeon, I have encountered four major events that transformed the neurosurgical field as well as the management of patients with cerebral diseases; the operating microscope followed by rapid advancement of its techniques and equipment, the advent of CT scanning and later MR imaging, stereotactic radiosurgery, and interventional neuroradiology. Progress in these four innovations continues even now, constantly changing our neurosurgical practices. Stereotactic radiosurgery is the least invasive of these advanced treatment modalities and has become our basic neurosurgical management tool in recent decades. The late Professor Lars Leksell initially used the gamma knife to treat functional disorders. However, in the four decades since, arteriovenous malformations, benign brain tumors and brain metastases have become the most common indications for gamma knife radiosurgery. Although there has been competition between conventional neurosurgery and radiosurgery, most neurosurgeons nowadays recognize these two treatment modalities as being complementary. Furthermore, it is noteworthy that the concept of gamma knife radiosurgery, described as irradiating a lesion selectively while minimizing the dose to surrounding normal tissues, is increasingly being applied to extracranial pathologies, i.e. spinal tumors and cancers of the lung, liver, pancreas, prostate, and so on.

My hope is that readers will obtain accurate knowledge of gamma knife radiosurgery from this volume, utilizing it for better patient management with good quality-of-life maintenance.

As the host of the 6th Congress of the International Stereotactic Radiosurgery Society (ISRS) in Kyoto in 2003, I appreciate Masaaki Yamamoto, MD, PhD and the four coeditors for publishing this volume to commemorate the ISRS Kyoto Congress.

Kintomo Takakura, MD, $\mathrm{PhD}$

Honorary Editor

Tokyo, Japan 



\section{Preface}

Why should a whole book be devoted to Japanese gamma knife radiosurgery experiences? First and foremost, approximately one fifth of the gamma knives in operation worldwide are in Japan, and approximately one fourth of patients undergoing gamma knife radiosurgery worldwide are treated in Japan. Second, as compared with the United States and European countries, the majority of patients are meticulously followed using high-quality neuroimaging techniques for longer periods after treatment, as Medicare costs are generally lower than in western countries. This follow-up is considered to be very important in managing a patient after radiosurgical treatment, i.e. both actual treatment results and real complication rates are thoroughly documented in Japan. Finally, most neurosurgeons as well as co-medical personnel have made dedicated and ongoing efforts to master up-to-date techniques and recent advances in managing patients by participating in meetings and training courses specially designed for gamma knife radiosurgery. In fact, as detailed in the chapter by Mr. Stephan Otto, since the Japanese Leksell Gamma Knife Society was established in the early 1990s, these meetings and/or training courses have been held annually; all participants have been able to share their clinical experiences as well as their knowledge of the basic sciences involving radiobiology and novel techniques. As a consequence of these activities, gamma knife radiosurgery in Japan is being maintained at a high level.

Each contributor has more than 10 years' experience with gamma knife radiosurgery and has been recognized internationally as a leader in his specialized field. My hope is that leaders in this field, not only in Japan but also worldwide, will gain an understanding of the full reality of gamma knife radiosurgery: good results, unfavorable results and various complications. Publication of this volume was initially planned to commemorate the 6th Congress of the International Stereotactic Radiosurgery Society held in Kyoto in 2003. Although, for a variety of reasons, it has 
taken some 5 years to get to publication, each chapter still contains new and worthwhile information.

Finally, I would like to thank Bierta E. Barfod, MD and Dr. Thomas Karger and his staff who helped bring this volume to completion.

Masaaki Yamamoto, MD, PhD

Editor

Hitachi-naka, Japan 